\title{
Study of Problems and Prospects Drip Irrigation System on Chilli Crop in Barwani District of M.P. India
}

\author{
Ravi Bhuriya ${ }^{1}$, Dr. Sandhya Choudhary ${ }^{2}$, Dr. V.K. Swarnakar ${ }^{3}$ \\ ${ }^{1}$ M.Sc. Extension Education Final Year Student 2015 \\ ${ }^{2}$ Associate Professor Extension Education, College of Agriculture, Indore \\ ${ }^{3}$ Professor \& Head Extension Education, College of Agriculture, Indore
}

\begin{abstract}
Drip irrigation is basically precise and slow application of water in the form of discrete continuous drops, sprayed through mechanical devices, called emitters into the root zone of the plant". Singh (1995) reported that by the drip system of irrigation, water reaches the roots drop by drop and hence, it is an economic method of irrigation in all seasons. The problems analysis was reported based on the through studies of opinion survey of sample respondents adopting the drip irrigation system in study area. Thus, the generalizations of result are the feedback. Above table revealed the major constraints as perceived by the respondents are as per the frequency level of respondents and ranked accordingly the views at the time of collecting data were hard management practices in drip irrigation system.
\end{abstract}

Keywords: Drip Irrigation, Chilli Crop, problems and prospects

\section{Introduction}

The water use efficiency under conventional flood method of irrigation, which is predominantly practiced in Indian agriculture, is very low due to substantial conveyance and distribution losses. Recognizing the fast decline of irrigation water potential and increasing demand for water from different sectors, a number of demand management strategies and programmes have been introduced to save water and increase the existing water use efficiency in Indian agriculture. One such method introduced recently in Indian agriculture is micro-irrigation, which includes both drip and sprinkler method of irrigation. Micro-irrigation (MI) is proved an efficient method in saving water and increasing water use efficiency as compared to the conventional surface method of irrigation, where water use efficiency is only about $35-40$ percent.

Drip irrigation technology permits the efficient use of water and can help maximize the use of semi arid lands for agricultural use. Drip irrigation system is extremely profitable as it saves $40-70$ per cent water as compared to surface irrigation method i.e. flood, sprinkler, furrow. The drip method also reduces labour cost and protects the plants from diseases by minimizing humidity in atmosphere. Besides, soluble fertilizers can also be applied with irrigation water. Thus, drip irrigation has become a means of hi-tech Agriculture/ Horticulture and precision farming. The efficiency of water is enhanced by $90-95$ per cent under drip irrigation system.

In Madhya Pradesh Barwani district is known for their peculiar character of black soil. The main crops of this area are cotton and chilli, as well as fruits and other vegetables also but cotton and chilli are the main source of income to the farmers. The annual average rainfall rate of last two years was $721.4 \mathrm{~mm}$ (Agricultural Statistics, Bhopal, M.P.) hence water scarcity and sources of irrigation were not sufficient for the cultivation of crops influentially and thus the farmers are to be suffered to this problem. Therefore, it was necessary to investigate the constraints and prospects of drip irrigation system by the chilli growers in present study.

\section{Objective}

To find out the problems and prospects of drip irrigation system in view of chilli growers.

\section{Review of Literature}

Patel (2012) found that hard management practices in drip irrigation system (Ist ranked) viewed by 50.00 per cent of respondents followed by lack of credit facilities for drip irrigation system (IInd ranked) viewed by 49.17 per cent, Risk in adoption of drip irrigation system (IIIrd ranked) viewed by 48.33 per cent, preferring adoption of traditional irrigation system (IVth ranked) viewed by 45.00 per cent, lack of capital for adoption of drip irrigation system ( Vth ranked) viewed by 38.33 per cent, drip irrigation system be costly (VIth ranked) viewed by 35.83 per cent, Lack of technical knowledge about drip irrigation system (VIIth ranked) viewed by 35.00 per cent, Lack of training facilities regarding drip irrigation system (VIIIth ranked) viewed by 31.67 per cent, Lack of information about drip irrigation system (IXth ranked) viewed by 29.17 per cent, Lack of proper knowledge for adoption of drip irrigation system (Xth ranked) viewed by 24.17 , Lack of proper facilities regarding drip irrigation system (XIth ranked) viewed by 20.83 percent of the total respondents respectively.

Patel (2012) found that majority (55.83 per cent) of the respondents suggested that Drip Irrigation System should be provided at time followed by $(52.50$ per cent $)$ easily providing the loan at low interest level and time, (50.83 per cent) Drip Irrigation System should be provided at low cost, 


\section{International Journal of Science and Research (IJSR) \\ ISSN (Online): 2319-7064 \\ Index Copernicus Value (2013): 6.14 | Impact Factor (2014): 5.611}

(48.33 per cent) the extension workers should be provided proper guidance at time, (45.83 per cent) extension facilities should be available on demonstration and visiting basis, (42.50 per cent) there should be proper motivation for installation of Drip Irrigation System, (40.00 per cent) credit repayment should be easy, (31.67 per cent) there should be organized training programme and demonstration regarding technical knowledge of Drip Irrigation System and (30.00 per cent) there should be appointed special person for regular checking and management of Drip Irrigation System were the main suggestions as given by the respondents for solving the constraints.

Meti (2013) assessed the constraints in drip irrigation adoption and revealed that, farmers using drip irrigation were having constraints like complicated procedures in getting loan, delay in sanction of loan, non availability of soluble fertilizers, inadequate supply of electricity, choking of laterals and drippers, initial investment is high, inadequate follow up services by drip agencies, nonavailability of quality materials and rodents damage to the laterals respectively.

Vermani et. al. (2014) revealed that regarding constraints, most of cotton grower reported irregular power supply (100 per cent), not getting actual price ( 72 per cent) and loss of crop due to attack of 'ukhera' disease (15 per cent) and get adulterated seeds ( 5 per cent).

\section{Material \& Methods}

Barwani Block of Barwani district was selected purposively for the present study because the majority of the farmers used Drip Irrigation System. For this study, the random sampling technique was used for selection of villages and proportionate random sampling for selection of respondents. 10 villages were selected randomly out of the list of villages in the block using drip irrigation system. Master list of farmers using drip irrigation system in the selected villages was prepared and a sample of 120 farmers were selected using proportionate sampling technique.

\section{Problems and prospects of drip irrigation system in view of chilli growers}

The data regarding adoption level of drip irrigation system was found to be as medium level followed by high and low respectively. The adoption at medium and low level was due to many problems confronted by respondents. The main problems are presented in Table bellow:

Table: Problems of drip irrigation system in view of chilli growers

\begin{tabular}{|c|l|c|c|c|}
\hline S.No. & \multicolumn{1}{|c|}{ Problems } & $\begin{array}{c}\text { Frequency } \\
(\mathrm{N}=120)\end{array}$ & Percentage & Rank \\
\hline 1. & Hard management practices in drip irrigation system & 117 & 97.50 & I \\
\hline 2. & Lack of credit facilities for drip irrigation system & 112 & 93.33 & II \\
\hline 3. & Risk in adoption of drip irrigation system & 110 & 91.66 & III \\
\hline 4. & Preferring adoption of traditional irrigation system & 99 & 82.50 & IV \\
\hline 5. & Lack of capital for adoption of drip irrigation system & 98 & 81.66 & V \\
\hline 6. & Drip irrigation system be costly & 92 & 76.66 & VI \\
\hline 7. & Lack of technical knowledge about drip irrigation system & 85 & 70.83 & VII \\
\hline 8. & Lack of training facilities regarding drip irrigation system & 75 & 62.50 & VIII \\
\hline 9. & Lack of information about drip irrigation system & 60 & 50.00 & IX \\
\hline 10. & Lack of proper knowledge for adoption of drip irrigation system & 50 & 41.66 & X \\
\hline 11. & Lack of proper facilities regarding drip irrigation system & 44 & 36.67 & XI \\
\hline
\end{tabular}

The problems analysis was reported based on the opinion survey of the sample respondents. Thus, the generalizations of result are the feedback through respondents adopting the drip irrigation system in study area. The above table revealed the major constraints as perceived by the respondents are as per the frequency level of respondents and ranked accordingly the views at the time of collecting data were hard management practices in drip irrigation system ( $\mathrm{I}^{\text {st }}$ ranked) viewed by 97.50 per cent of respondents followed by lack of credit facilities for drip irrigation system (II ${ }^{\text {nd }}$ ranked) viewed by 93.33 per cent, Risk in adoption of drip irrigation system (III ${ }^{\text {rd }}$ ranked) viewed by 91.66 per cent, preferring adoption of traditional irrigation system ( $\mathrm{IV}^{\text {th }}$ ranked) viewed by 82.50 per cent, lack of capital for adoption of drip irrigation system $\left(\mathrm{V}^{\text {th }}\right.$ ranked) viewed by 81.66 per cent, drip irrigation system be costly ( $\mathrm{VI}^{\text {th }}$ ranked) viewed by 76.66 per cent, Lack of technical knowledge about drip irrigation system (VII ${ }^{\text {th }}$ ranked) viewed by 70.83 per cent, Lack of training facilities regarding drip irrigation system (VIII $^{\text {th }}$ ranked) viewed by 62.50 per cent, Lack of information about drip irrigation system ( $\mathrm{IX}^{\text {th }}$ ranked) viewed by 50.00 per cent, Lack of proper knowledge for adoption of drip irrigation system ( $\mathrm{X}^{\text {th }}$ ranked) viewed by 41.66 per cent, Lack of proper facilities regarding drip irrigation system $\left(\mathrm{XI}^{\text {th }}\right.$ ranked) viewed by 36.67 per cent of the total respondents respectively

\subsubsection{Suggestion regarding removal of problems.}

For removing of these problems expressed by the respondents following suggestion were made. Table showed the suggestions expressed by the respondents to remove the problems 


\section{International Journal of Science and Research (IJSR)}

ISSN (Online): 2319-7064

Index Copernicus Value (2013): 6.14 | Impact Factor (2014): 5.611

Table: Suggestions confronted by the respondents for solving the problems

\begin{tabular}{|c|c|c|c|c|}
\hline S.N. & Suggestions & $\begin{array}{l}\text { Frequency } \\
(\mathrm{N}=120)\end{array}$ & Percentage & Rank \\
\hline & DIS should be provided at time & 97 & 80.83 & $\mathrm{I}$ \\
\hline 2. & Easily providing the loan at low interest level and time & 91 & 75.00 & II \\
\hline 3. & DIS should be provided at low cost & 87 & 72.50 & III \\
\hline 4. & The extension workers should be provided proper guidance to the maintenance. & 85 & 70.83 & IV \\
\hline 5. & Demonstration and visiting of experts. & 83 & 69.16 & $\mathrm{~V}$ \\
\hline 6. & There should be proper motivation for installation of DIS & 65 & 54.16 & VI \\
\hline 7. & Credit repayment should be easy. & 60 & 50.00 & VII \\
\hline 8. & $\begin{array}{l}\text { There should be organized training programme and demonstration regarding technical } \\
\text { knowledge of DIS. }\end{array}$ & 45 & 37.50 & VIII \\
\hline 9. & There should be appointed person for regular checking and management of DIS & 35 & 29.16 & IX \\
\hline
\end{tabular}

In the present study respondents were asked for minimizing the problems regarding drip irrigation system. The following suggestions were confronted by the respondents to overcome the problems.

The majority of the respondents suggested that Drip Irrigation System should be provided at time (80.83 per cent and ranked I) followed by easily providing the loan at low interest level and time (75.00 per cent and ranked II), Drip Irrigation System should be provided at low cost (72.50 per cent and ranked III), extension workers should be provided proper guidance at time (70.83 per cent and ranked IV), extension facilities should be available on demonstration and visiting basis (69.16 per cent and ranked V), there should be proper motivation for installation of Drip Irrigation System (54.16 per cent and ranked VI), credit repayment should be easy (50.00 per cent and ranked VII), there should be organized training programme and demonstration regarding technical knowledge of Drip Irrigation System (37.50 per cent and ranked VIII) and there should be appointed special person for rregular checking and management of Drip Irrigation System (29.16 per cent and ranked IX).

Table: Benefit Cost ratio of chilli crop growers:

\begin{tabular}{|l|c|}
\hline \multicolumn{1}{|c|}{ Economic Parameters } & Beneficiaries \\
\hline Cost of Cultivation (Rs./ha.) & 59000 \\
\hline Yield (q/ha.) & 120 \\
\hline Gross income (Rs./ha.) & 180000 \\
\hline Net income (Rs./ha.) & 121000 \\
\hline Benefit cost ratio (Rs./ha.) & $\mathbf{1 : 3 . 0 5}$ \\
\hline
\end{tabular}

The data indicate in table shows that the cost of cultivation in the beneficiaries was found to be $59000 \mathrm{Rs}$./ha. The yield of beneficiaries was found to be $120 \mathrm{q} / \mathrm{ha}$. The gross income of beneficiaries was $180000 \mathrm{Rs} . / \mathrm{ha}$. and the net income was found to be $121000 \mathrm{Rs}$./ha. In beneficiaries. Thus, the benefit cost ratio (B:C ratio) analysed after the study was found to be $1: 3.05$ in beneficiaries.

\section{References}

[1] Meti, C. B. (2013). Benefits of drip irrigation and constraints in drip irrigation adoption in Dharwad district of Northern Karnataka. Department of Agricultural Engineering, Agriculture College, University of Agricultural Sciences, Dharwad ,Karnataka, India. Environment and Ecology; 2013. 31(2A):632-636. 7 ref.

[2] Patel, N. and S. Choudhary (2013) Study on adoption of eco-friendly management practices by vegetable growers in Indore Block of Indore District (M.P.). IOSR Journal of Agriculture and Veterinary Science, 2319-2380,pISSN: 2319-2372. Volume X, Issue X (Mar. - Apr. 2013).

[3] Patel.Y. S. (2012). Study on adoption behavior of farmers towards Drip Irrigation System in Khargone Block of Khargone District (M.P.). College of Agriculture ,Indore. M.Sc. (Ag.) Thesis RVSKVV, Gwalior.

[4] Venkataramalu, 2003, A study on the knowledge level, adoption and marketing behaviour of chilli growers in Guntur district of Andhra Pradesh. M.Sc.(Agri.) Thesis, Univ. Agric. Sci., Dharwad.

[5] Vermani S.; K. Jatesh; Deep Punia and Rashmi (2014). Adoption and impact assessment of conservation agriculture technologies with special reference to growing of cotton crop with drip irrigation. Department of Sociology, CCS, Haryana Agricultural University, Hisar, India. Journal of Cotton Research and Development; 2014. 28(1):154-160. 8 ref. 